\title{
Cartografías del reverso. Las palabras ocultas de la fotografía de arquitectura moderna
}

\author{
Iñaki Bergera \\ Universidad de Zaragoza \\ ibergera@unizar.es
}

RESUMEN: Mi experiencia investigadora en el ámbito de la fotografía de arquitectura moderna, me ha permitido documentar numerosas fotografías y constatar que es en el reverso de la propia copia fotográfica de época donde se inscriben las palabras que paradójicamente soportan la identidad de la imagen. Accedemos a ese espacio escondido del dorso para justificar teórica y conceptualmente su profundo alcance y su interpretación gráfica y cartográfica, poniendo en valor por primera vez la trascendencia de los textos, signos, gráficos, etc., que allí han permanecido ocultos.

PALABRAS CLAVE: Fotografía; Arquitectura moderna; Reverso; Texto.

\section{Mapping the Verso. Hidden Words of Modern Architectural Photography}

ABSTRACT: My research experience in the field of modern architecture photography, has allowed me to document numerous photographs and observe that is on the verso of the vintage photographic print where the words that paradoxically support the identity of the image are registered. We access that hidden space of the reverse to theoretical and conceptually justify its challenging scope and its graphic and cartographic interpretation, adding value for the first time to the importance of texts, signs, graphics, etc., which have remained hidden there.

KEYWORDS: Photography; Modern Architecture; Verso; Text.

Recibido: 10 de abril de 2017 / Aceptado: 25 de mayo de 2017.

Lo que me parece más útil es cómo el acto de escribir gobierna las asociaciones necesarias para mirar cada fotografía. La descripción proporciona la interpretación. Si la descripción es necesaria para completar el significado de una fotografía o para interpretar el aspecto visual identificando sus elementos en palabras, podemos preguntarnos quién está calificado para describirlo. La respuesta es, cualquiera que esté dispuesto a mirar (Price, 1994: 5).

La fotografía es una imagen, una reproducción y todo lo que en ella se observa y de ella se puede deducir y relatar. Es un documento y es también una evocación al tiempo y la memoria. Pero una fotografía es, antes que nada, un objeto, una entidad material. A pesar de su naturaleza reproductible, tal como analizó Walter Benjamin en su célebre texto, una copia en papel es, o puede ser, una pieza única. La irrupción de la fotografía digital puso en crisis esta aseveración desmaterializando de alguna manera la identidad de la imagen pero, sin duda, la fotografía analógica -el negativo, el positivo, la diapositiva, etc.- tiene una naturaleza química y física que imposibilita sustraerla de su entidad objetual y ontológica. Si bien entendemos que «la fotografía» es la imagen visual, la representación más o menos parcial, más o menos fidedigna que vemos impresa en el anverso, nos parece estimulante apostar por conferir un valor irrefutable -complementario pero también autónomo- a lo que la fotografía como objeto esconde tras de sí.

Cómo citar este artículo: BERGERA, Iñaki: "Cartografías del reverso. Las palabras ocultas de la fotografía de arquitectura moderna", Boletín de Arte-UMA, n. 38, Departamento de Historia del Arte, Universidad de Málaga, 2017, pp. 75-86, ISSN: 0211-8483, DOI: http://dx.doi.org/10.24310/BoLArte.2017.v0i38.3221 
Por razones de investigación he tenido durante años acceso documental en archivos de España y de otros países a un gran número de fotografías originales de arquitectura moderna1. Seguramente el objetivo de este texto se podría también sustanciar en referencia a otros géneros fotográficos o a otros contextos temporales, pero es en este ámbito que conocemos donde podemos avalar el argumento de forma concreta y justificada. La información impresa en el reverso de la propia fotografía de arquitectura -esas fotografías que conformaron icónicamente nuestro imaginario arquitectónico moderno (Isasi, 2014)- es en muchas ocasiones la única fuente documental que permite catalogarla. Fruto de esta investigación se ha conseguido hacer un inventario de los contenidos -auténticos metadatos- que se repiten generalmente en sus reversos²: el nombre del fotógrafo y del arquitecto, la firma del fotógrafo, el nombre del cliente o de la publicación, direcciones postales, el nombre del edificio y su localización y las fechas originales o de reimpresión, así como correcciones y enmiendas sobre los datos existentes [1]. En el mejor de los casos, la cartografía de esas traseras queda también configurada visualmente por un conjunto de elementos de naturaleza gráfica como números, líneas, indicación de reencuadres e incluso trazas de adhesivados previos. En sí mismo y en muchas ocasiones, este constructo visual tiene un interés gráfico innegable: muchos reversos son, en su espontaneidad, estéticamente estimulantes y aparecen cargados sin quererlo de expresividad artística [2].

\section{Puesta en historia y valor del archivo}

Nuestro interés por las traseras fotográficas se puede circunscribir también dentro de lo que Buchloh (1990) denominó "estética de la administración», una aproximación conceptual que se estructura por sistemas concertados de clasificación. Las anotaciones del reverso indexan la fotografía de arquitectura para su catalogación de archivo. El reverso oculto es portador de la ficha policial y el historial clínico de la imagen. Prestar atención a estas traseras se justifica además desde la necesidad perenne de repensar la historia de la fotografía que tanto preocupa a los teóricos e investigadores del medio (Fontcuberta, 2002). Esta historia se percibe hasta la fecha polarizada por la versión que privilegia a los fotógrafos -y por tanto al concepto de autoría- frente a la que pivota sobre las fotografías, es decir, la que convino a los conservadores y coleccionistas frente a la que satisface a los críticos de arte.

Este «descubrimiento» puede ayudar a que los archivos que conservan las fotografías de arquitectura moderna reescriban transversalmente una historia pluridisciplinar casando ambas atenciones [3]. Mirar los reversos implica de esta manera entender las fotografías como objetos de estudio y no únicamente como instrumentos de estudio. Si esto es un valiosa contribución refiriéndonos a la fotografía en un sentido amplio, en el caso de la fotografía de arquitectura profesional esta querencia dignifica de alguna manera una práctica fotográfica menospreciada disciplinarmente por su naturaleza netamente documental e instrumental. Por referirnos a un caso paradigmático, Le Corbusier empleaba en no pocas ocasiones la trasera de las fotografías para hacer anotaciones operativas. La condición instrumental y metodológica de la fotografía al servicio de la proyectación implica literalmente anotar en su reverso, como si de una postal se tratara, apuntes que infieren trasformaciones en lo que la fotografía revela en relación al espacio fotografiado (Gargiani, 2014).

Este «mirar detrás» contribuye a una suerte de puesta en historia que obliga a repensar la fotografía y que subraya la importancia de revelar y desvelar, material y visualmente, aquellos datos que hasta ahora solo interesaban al archivo pero no al museo, a la catalogación pero no a la investigación, un cruce historiado de narrativas entre las imágenes y sus textos: "Las imágenes hacen imaginable ("ilustran") lo que cuentan los textos, y los textos hacen concebible (“cuentan") lo que representan las imágenes. La dialéctica "interna" y "externa" de los textos y las imágenes constituye buena parte de la dinámica que llamamos "historia"» (Flusser, 1984: 103).

\section{Nueva cartografía}

Cuando el capitán del poema de Lewis Carroll The Hunting of the Snark (1874) ofrece a sus marineros un mapa sin signos convencionales ni referencia alguna a tierra, estos se sienten reconfortados al disponer del mejor mapa posible para su navegación marina: un espacio en blanco enmarcado con la escala y la presencia de los puntos cardinales. El blanco del reverso fotográfico nos refiere a la ausencia de la imagen a la 
1. Dorso de una fotografía de Kindel del Poblado de Caño Roto

(Madrid, 1957-1969), obra de los arquitectos José Luis Î́niguez de Onzoño y Antonio Vázquez de Castro perteneciente al archivo de Carlos Flores y publicada en su libro de 1961 Arquitectura Española Contemporánea (Aguilar, Madrid)

2. Aspecto de la parte posterior de una fotografía de autor desconocido del proyecto Home of the Future de Alison y Peter Smithson (Londres, 1956). Se apunta al interés gráfico y plástico de las marcas dejadas por un adhesivado previo de la fotografía. Collection Canadian Centre for Architecture, Montréal. DR1995:0042
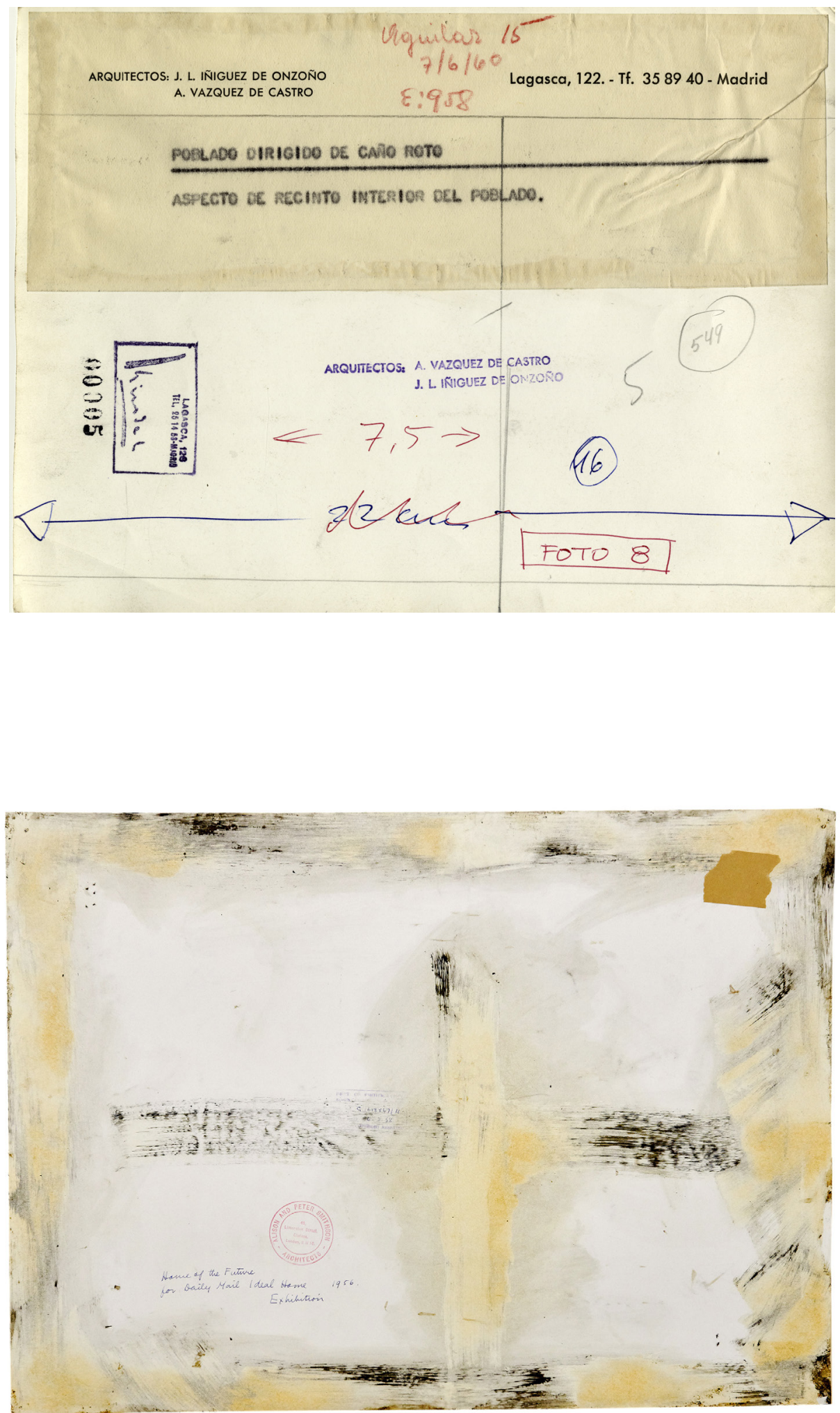


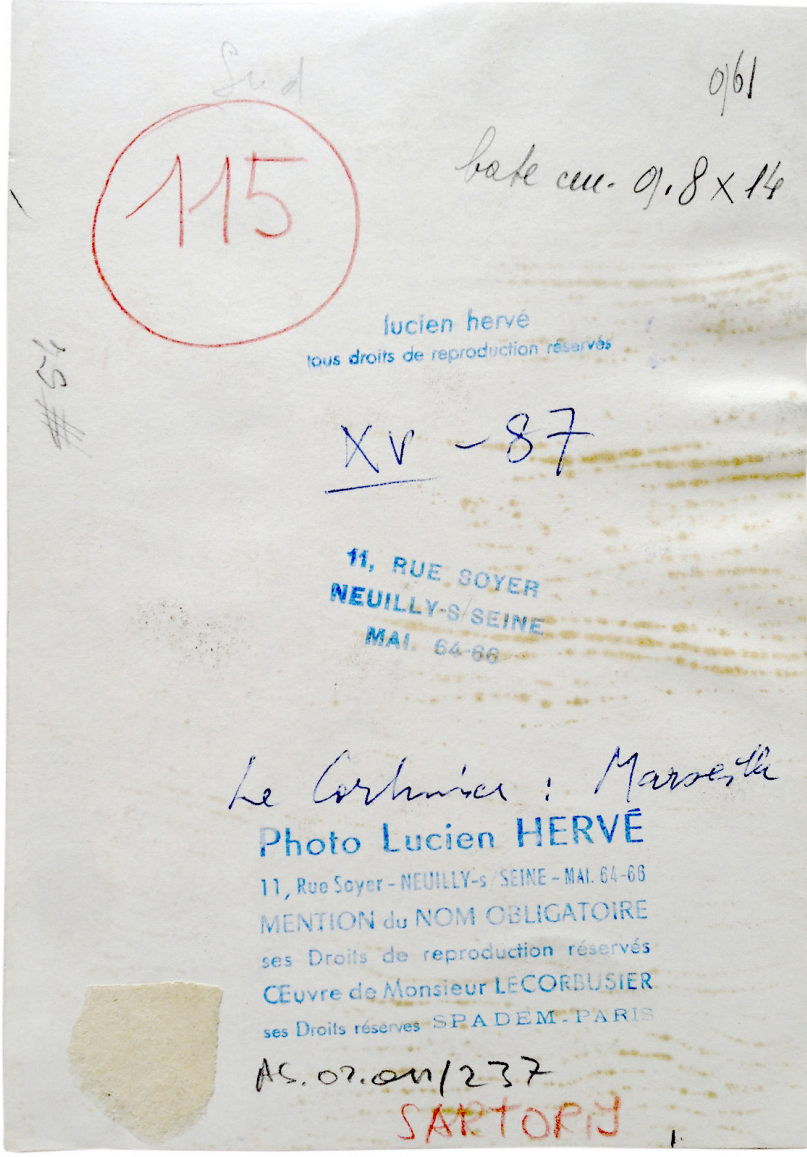

3. Reverso de una fotografía (1952) realizada por Lucien Hervé de la Unité d'habitation de Marsella de Le Corbusier. Fondo Alberto Sartoris, ACM EPFL, AS 0172.02.0011/237

que sirve. El blanco, en el lenguaje de los mapas, no es una representación de la nada. Los silencios cartográficos contienen claves para la navegación y, en nuestro caso, para la lectura de la imagen fotográfica de arquitectura. El vacío nos habla del lleno que no vemos pero intuimos. Las leyendas de los mapas medievales debían enfrentarse al espacio en blanco del mundo inexplorado. Como se descubrió, tampoco aquí el blanco es sinónimo de vacío. Una línea, un límite, señalan gráficamente la distancia entre lo conocido y lo desconocido. Para disuadir a los navegantes de adentrarse en ese espacio blanco, la leyenda del mapa advertía: «A partir de aquí, monstruos» (Del Molino, 2013).

Nuestros «monstruos» son apenas unos datos, un trazo o una línea: ese conjunto de signos y palabras -verdaderas cicatrices de su historia- que actúan de facto como un hipertexto que nos permite leer y analizar la sustancia visual e interpretativa de la fotografía a la que sirven pero que no vemos. Este vacío, habitado por palabras, es el comienzo del espacio semántico, como apuntaba Perec (2007: 33): «Así comienza el espacio, solamente con palabras, con signos trazados sobre la página blanca. Describir el espacio, nombrarlo, trazarlo, como los dibujantes de portulanos que saturaban las costas con nombres de puertos, nombres de cabos, nombres de caletas, hasta que la tierra solo de separaba del mar por una cinta de texto continua» [4].

Robert Smithson dibujó en 1969 (firmado en 1970) Surd View for an Afternoon sobre un papel con coordenadas polares y una cuadrícula concéntrica, un mapa mental, intencional y proyectual de sus trabajos de Land Art de aquellos años. Líneas, vectores, conceptos y referencias al paisaje conforman una cartografía celeste que trata de justificar la manera de situar empíricamente sus intervenciones espirales en el territorio. Nos atrevemos a entender este dibujo de Smithson como la trasera de su obra, aquella que trasciende a su existencia y autonomía pero que, conocida, contiene diagramáticamente los datos que la avalan y explican. Tautológica por un lado, por una suerte de redundancia conceptual, pero irracional por otro, este ideograma cartográfico interpreta el pulso figuración-abstracción como lo hace la imagen fotográfica en relación a la entropía de textos escondidos que la completan y describen. Explica Smithson: «El contenido generalmente implica algún tipo de aspecto representacional que trato de evitar. El no-lugar es una abstracción que representa al lugar. No parece el lugar; el no-lugar no es como el lugar aunque apunta hacia él» (Flam, 1996: 199).

\footnotetext{
Vivimos bajo una lluvia ininterrumpida de imágenes; los media más potentes no hacen sino transformar el mundo en imágenes y multiplicarlas a través de una fantasmagoría de juegos de espejos: imágenes que en gran parte carecen de la necesidad interna que debería caracterizar a toda imagen, como forma y significado, como capacidad de imponerse a la atención, como riqueza de significados posibles. Gran parte de esta nube de imágenes se disuelve inmediatamente, como los sueños que no dejan huellas en la memoria (Calvino, 1994: 73).
}

Seguramente los textos ocultos tras las fotografías operen como las únicas huellas remanentes en la satura- 
4. Dorso de una fotografía (ca1918) del la casa Edna S. Purcell (Minneapolis, Minnesota, 1913) significativa por la cantidad de texto que contiene. Collection Canadian Centre for Architecture, Montréal. PH1991:0269

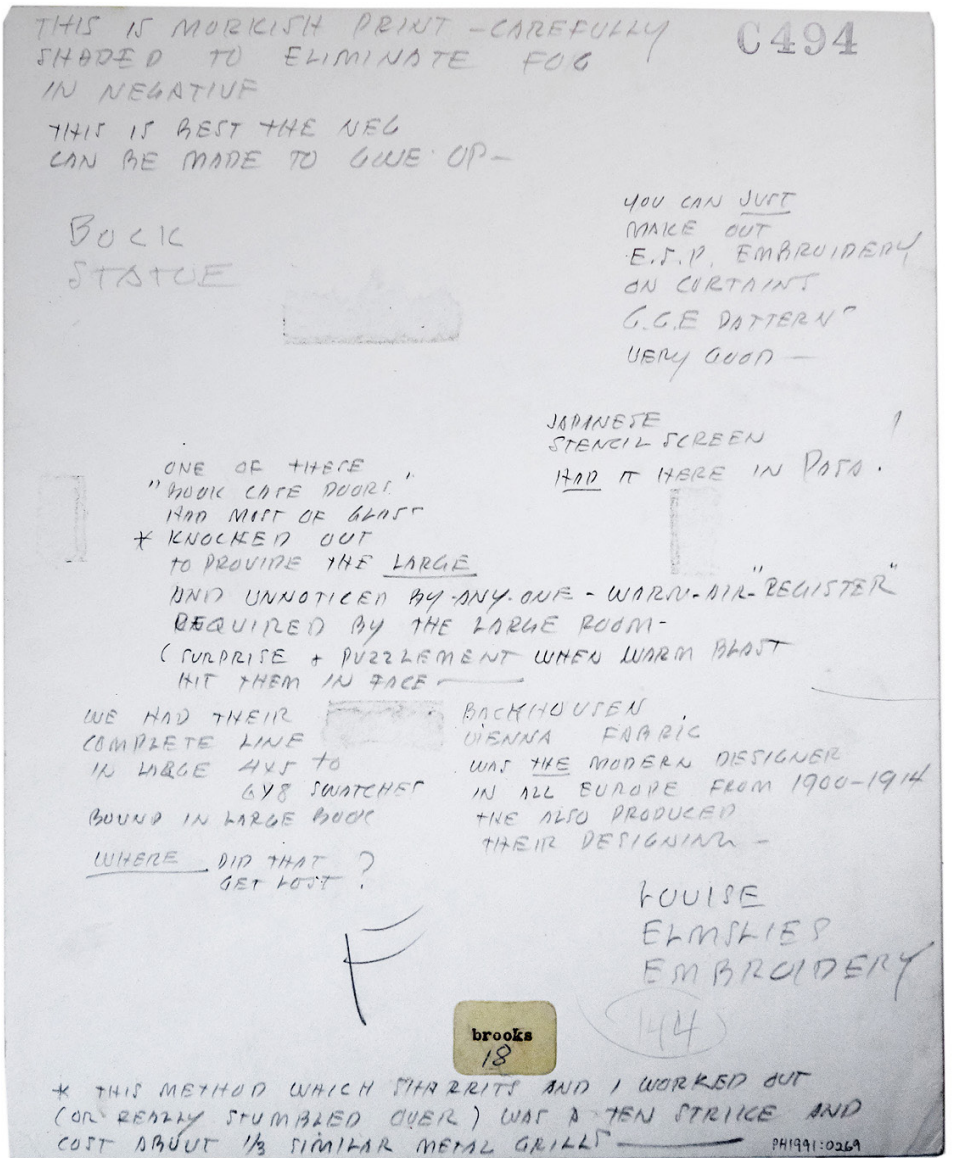

ción de imágenes -también de arquitectura- que nos regaló la modernidad. Para evitar así la inmediatez del consumo y la disolución instantánea de lo visual, volteamos las fotografías y, desde una memoria operativa, las relegamos en silencio. La imagen, según Ranciere (2007), es «un vehículo para un silencioso discurso que nos esforzamos en traducir en frases... la imagen nos habla precisamente cuando es silenciosa, cuando ya no nos transmite ningún mensaje». Las traseras y la información que contienen nos remiten a la definición que Umberto Eco hace de «obra abierta», aquella cuyo sentido y finalización depende del espectador. Revisar esas traseras nos sumerge en las prácticas de la «arqueología del saber visual», según Didi-Huberman (2010), el entrelazamiento abierto de relaciones cruzadas entre textos e imágenes construyendo así una cartografía de la memoria (Tartás y Guridi, 2013). Nos ayuda a elaborar también un nuevo atlas interpretativo que privilegie la valoración de las evidencias en la construcción del mito moderno de la supremacía de la imagen en la arquitectura.

\section{Revelar lo escondido, ocultar lo visible}

La obra Stones, Monument against Racism (1993) del artista Jochen Gerz es conocida como el «monumento invisible». Más de dos mil adoquines del pavimento de una plaza llevan grabados en su base los nombres de los cementerios de las víctimas del holocausto permaneciendo, por tanto, ocultos a la vista. El Vertical Earth Kilometer (1977) de Walter de Maria es una barra de metal enterrada de un kilómetro de largo. En la superficie solo se ve el corte del diámetro de la barra. Únicamente el título, las palabras, nos remiten al objeto de la obra de arte. Los artistas Joana Hadjithomas y Khalil Joreige presentaron en la Bienal de Venecia 2015 su proyecto Latent 
Images. Diary of a Photographer. El proyecto consistía en la lectura pública de un libro que contenía detalladas descripciones de fotografías tomadas en Beirut entre 1977 y 2006 que nunca fueron reveladas y que, por tanto, dan pie a su evocación imaginaria a partir del texto que las describe.

Estas referencias del arte conceptual nos ayudan a vislumbrar y realzar el interés del tema. Frente a la imposición moderna de lo retiniano, mirar las traseras de las fotografías persigue profundizar en el territorio de lo verbal como condensador de la dimensión velada y latente de la imagen. Se subraya el papel de lo oculto y de sus trazas preexistentes. La historia de la arquitectura se ha estructurado y perfilado mediante imágenes, pero estas fotografías, físicamente, ocultan palabras que esconden historias. Nos asomamos así a la cara oculta de la luna para ver las fotografías sin verlas, escudriñar, sin imágenes, las palabras escondidas que nos hablan de ellas:

En la obra velada la parte oculta de la misma no necesariamente tendría por qué existir físicamente, pues está irremediablemente oculta y sólo podemos saber de ella a través del lenguaje. En extremo, incluso aquello que se nos dice o insinúa que hay detrás de la ocultación, podría ser perfectamente otra cosa, podría no corresponder con lo que se nos dice. En ambos casos, inexistencia material de la parte velada o no correspondencia con lo formulado, el ser de la obra no se resentiría en absoluto (Reguera, 2008: 37).

La gran paradoja de nuestra contemporaneidad post-fotográfica, tal y como ha descrito Fontcuberta (2010), es que el exceso de imágenes e información termina por producir ceguera cultural y agnosia visual. La información ciega al conocimiento, la hipervisibilidad transforma lo obvio en invisible. Mirando tras la fotografía operamos de manera inversa, favoreciendo una suerte de ecología de la imagen: privilegiar los reversos significa acudir en rescate de lo físicamente invisible para darle visibilidad. Frente al carácter acabado y rígido de la imagen fotográfica, su trasera nos muestra con espontaneidad los nudos y mimbres de su tapiz. El artista brasileño Vik Muniz expuso en Holanda en 2016 su proyecto Verso, un conjunto de 15 reproducciones fidedignas y a tamaño natural de traseras de cuadros enmarcados de obras de arte señeras de Rembrandt, Picasso o Van Gogh. Mostrar la espalda de los lienzos, desvela sus precintos, sellos y alcayatas e invita al espectador a pensar y recrear la imagen mental del cuadro.

La visualización directa o recreada de la ortodoxa pulcritud de estas fotografías contrasta con la heterodoxa amalgama de información que habita a sus espaldas, en su backstage. Paradójicamente, lo que no se ve es lo que da validez notarial a lo visible. Si la fotografía, también la de arquitectura, ya no puede garantizar la verdad de lo representado, son estas inscripciones e informaciones que habitan en su trasera las que aportan objetividad y valor documental a la subjetividad propia de la imagen.

El hecho mismo de desvelar el reverso de las fotografías implica un ejercicio terapéutico al reducir la ansiedad de consumo de imágenes de arquitectura: la hubo durante las décadas Movimiento Moderno y la hay, exacerbada, en nuestros tiempos. Igualmente, mirar las traseras da satisfacción a las poéticas del deseo: dar la vuelta a la fotografía nos refiere al voyerismo de observar lo prohibido, aquello que permanece reservado y oculto a los ojos del espectador. El investigador, como el detective, podrá vencer la curiosidad que persigue la obtención de un dato y de una información, una pista en suma que pueda hacer de contratuerca al potencial interpretativo de la fotografía.

\section{Imágenes en circulación}

Es durante el Movimiento Moderno cuando la arquitectura se coaliga con la fotografía, y viceversa, para convertirse en el principal instrumento y catalizador de su expansión. Estas fotografías de arquitectura fueron hechas por y para circular, para ser diseminadas y publicarse en medios de divulgación disciplinares o generalistas. Tan importante como la fotografía en sí es el uso que de ella se hace. Y los reversos contienen el testimonio y el salvoconducto de ese uso. Es en el contexto de la publicación cuando la información encubierta encuentra toda su razón de ser en relación a la fotografía si bien, de manera habitual, este se limita a lo meramente enunciativo. «El vehículo para la interpretación de una imagen fotográfica publicada es su pie de foto, pero a menudo estos son culpablemente desinformativos, como si tanto la fotografía como el edificio que representa fueran absolutos atemporales» (Stamp, 2001: 1). Mucho más dinámica y adaptativa se muestra la información alojada en el reverso 
5. Trasera de una fotografía correspondiente a un proyecto de Pierre Jeanneret en Chandigarh. El sello del arquitecto indica «Photo de Pierre JEANNERET» mientras que, escrito a mano, se dice que el fotógrafo es Jeet Malhotra. Collection Canadian Centre for Architecture, Montréal. ARCH268940 OSG1 1560406

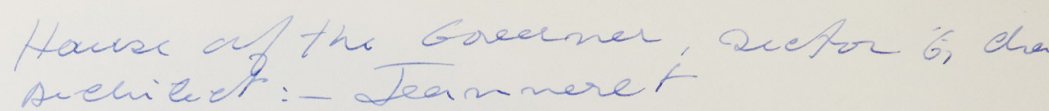

$$
\begin{aligned}
& \text { pento by jeet ma kwtre E\$ }
\end{aligned}
$$

Photo de Pierre JEANNERET

ARCHITECTE

11, rue Toepffer - GENĖVE

- Tous droits réservés -

MENTION OBLIGATOIRE

de las imágenes originales. Las traseras de esas fotografías viajeras muestran y ponen al descubierto los signos de su itinerancia: como sellos en el pasaporte o pegatinas en el baúl de viaje, contienen los datos necesarios para explicar desde dónde y a dónde fueron y en qué contextos vieron la luz.

En el reverso viaja, por tanto, el manual de uso de la fotografía: cómo reseñar la autoría y el copyright, cómo citar el nombre del proyecto, de qué manera y en qué formato y proporción publicarlo. Y lo más importante, en esas traseras se esconden enmiendas, comentarios y anotaciones que a modo de warnings o read me first alertan al receptor de esa imagen en circulación sobre datos que pueden cambiar su historia y matizar su uso [5]. Cotejar ese anejo manual de instrucciones con lo que finalmente publicado como pie de foto arroja datos sobre la veracidad y el rigor empleado en la ambiciosa tarea de la difusión arquitectónica [6].

6. Dorso de una fotografía de A.S. Koch de la Iglesia de la Coronación (Vitoria, 1958-1960), obra del arquitecto Miguel Fisac perteneciente al archivo de Carlos Flores y publicada en su libro de 1961 Arquitectura Española Contemporánea (Aguilar, Madrid). Entre las numerosas anotaciones y datos se puede leer, a lápiz, un mensaje destinado al impresor: «0jo, procurar sacar las líneas de cables que sujetan al Cristo»

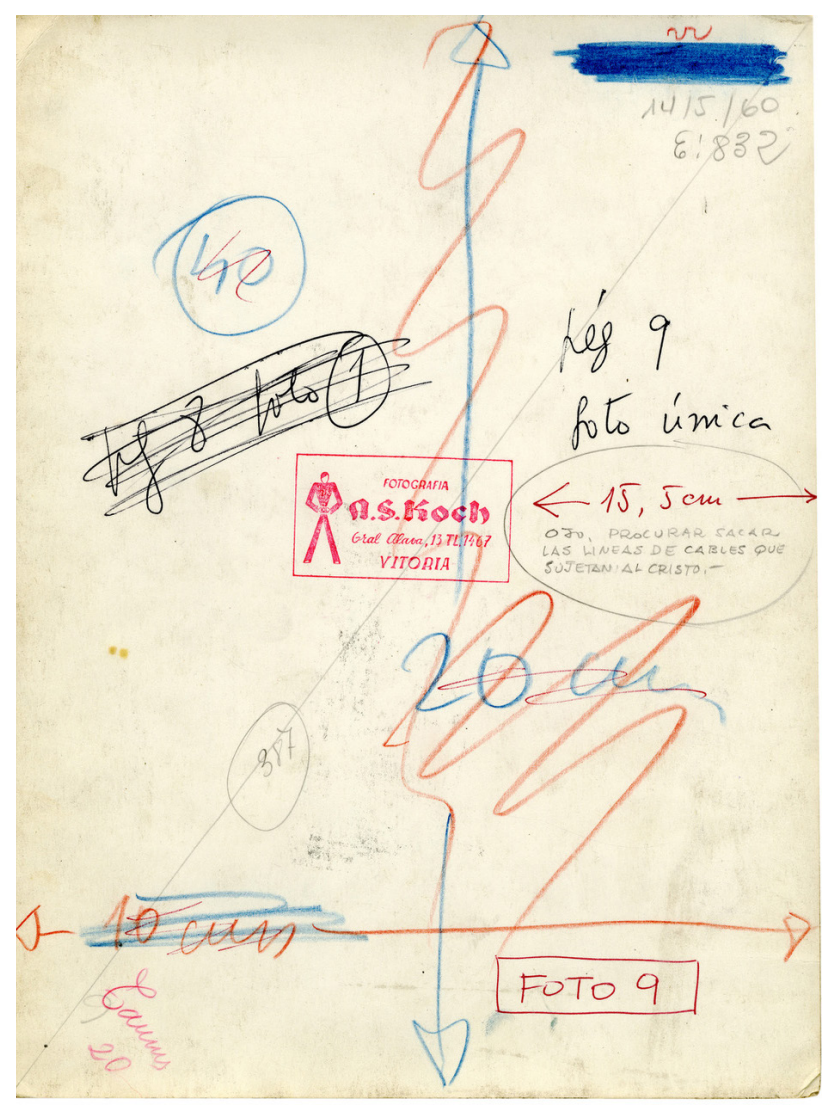




\section{Deconstrucción del texto y de la imagen fotográfica}

La subestimación de hasta qué extremo la propia imagen fotográfica debe leerse como construcción retórica es lo que da lugar a la idea de que el significado de la fotografía es demasiado impreciso en sí mismo y necesita fijarse mediante un pie de foto, para no perderse en la ambigüedad (Tagg, 2005: 241).

Podríamos entender este ejercicio como una nueva manera de interpretar el espacio fotográfico. La fotografía no es lo que se ve sino lo que se lee de ella en el amplio espacio semántico que la rodea. Al privilegiar el valor de los datos anejos a la propia imagen frente a su identidad visual, abandonamos la univalencia a favor de lo polivalente, la descripción jerárquica a favor de la rizomática. El hecho de que estas palabras adheridas físicamente al reverso de la imagen estén paradójica y simultáneamente separadas de ella obliga al investigador a crear «imágenes mentales» estableciendo nuevos vínculos y multiplicidades entre ambas [7]. El contenido y la forma de esas palabras introduce significados propios: «Lo más importante es que el texto que comenta la fotografía desvela, de manera definida y concreta, el espacio semántico oculto tras la fotografía. El texto enriquece el espacio semántico de la imagen y al mismo tiempo la dota de una importante cualidad marginal, lo que a su vez ilumina el texto» (Stigneev, 2002: 100).

La información velada, los metadatos ocultos de la fotografía, pueden entenderse también como una cita de la propia imagen. Juntos, la imagen por un lado y los textos y referencias por otro, constituyen incluso literalmente -por el hecho de tener que físicamente voltear el objeto fotográficouna suerte de acto performativo, aprovechando «esa convergencia entre texto y performatividad como vía de exploración que acerca las imágenes a la estética del texto y que acerca el texto a la sensibilidad de las imágenes» (Fernández Pello, 2014: 287).

Trabajamos arqueológicamente con fotografías arquitectónicas de la modernidad pero con herramientas críticas de nuestra era post-fotográfica. Esto lleva aparejado un cierto desmontaje de lo que fotografía es y, por tanto, puede reclamar unos nuevos valores epistemológicos. Esta deconstrucción, tal y como la entiende Derrida (2010), implica la sustitución y traslación de la lógica de la imagen a la lógica de las palabras, y viceversa.
Destacar el protagonismo del contexto, de estas inscripciones adheridas a la fotografía, supone también una ruptura de la tradicional lectura signo-estructura. Los textos ocultos hacen presente la ausencia de significados concretos de la imagen. Las inscripciones del reverso levantan acta de la vida y la naturaleza de la fotografía pero le restan libertad, la encapsulan y codifican: son el cenotafio de la imagen, de la muerte que toda fotografía es en relación a lo fotografiado. Una fotografía sin inscripciones apenas tiene valor y menos aún si no hay certeza ni de su autoría ni de la naturaleza o identidad de lo fotografiado. Sin esa información adicional escondida no hay memoria, la fotografía es amnésica.

\section{Leyendo el mensaje}

Este fue el momento en que el lenguaje invadió la problemática universal, el momento en que, en ausencia de un centro $u$ origen, todo se convirtió en discurso (Derrida, 2002).

No es infrecuente encontrar mensajes velados depositados en las traseras de las fotografías de arquitectura para avalar una suerte de contralectura de dichas imágenes y subrayar la importancia de esa relevante información parasitaria. El interés de estas palabras se puede analizar a la luz del mensaje lingüístico tal y como lo entiende Roland Barthes, con lo que el texto denota en sí mismo pero también por lo que connota en un contexto codificado. Estas informaciones ocultas no son resonancias de la fotografía sino en ocasiones muestras auténticas de su ADN que, no por ocultas, deben ser desatendidas para conocer la verdadera naturaleza de la fotografía de arquitectura.

Mientras que un pie de foto normal que acompaña a la fotografía publicada duplica y corrobora la denotación de la imagen, en nuestro caso «el texto produce un enteramente nuevo significado que se proyecta retroactivamente en la imagen, tanto como para parecer denotado allí» (Barthes, 1977: 530). Hasta el punto que, como hemos podido detectar en algún ejemplo concreto, el texto encontrado puede contradecir y desestabilizar la lectura de la imagen produciendo, apunta Barthes, una "connotación compensatoria» [8]. Nos encontramos en un camino dialéctico entre texto e imágenes, entre la función de anclaje destinada a evitar la polisemia y la función de relevo cuando texto e imagen tra- 
bajan en complementariedad. En palabras de Flusser (2001: 14), «si bien los textos interpretan las imágenes para disolverlas, también las imágenes ilustran los textos para hacerlos imaginables. Es verdad que el pensamiento conceptual analiza el pensamiento mágico para aniquilarlo, pero el pensamiento mágico se instala en el pensamiento conceptual para darle significado».

Los textos ocultos de las fotografías no capturan el significado de la imagen sino que, acaso, lo interpretan al tiempo que avalan o desmienten la información «natural» o «implícita» en la propia imagen. En otras palabras, estos textos tendrían que ver con los indicios de lo fotográfico, es decir, aquello que permite conocer o inferir en la lectura de la imagen lo que no se puede percibir a priori. Abundando en su condición física de anotación en el reverso de la imagen, estos indicios demandan una interpretación y permitirían, en ocasiones, desvelar el secreto que toda fotografía encierra. Únicamente una fotografía sin información vinculada se podría analizar de forma autónoma y desprejuiciada. Las inscripciones veladas no empiezan a operar donde la objetividad de la imagen acaba sino que se cuelan desde el principio en cualquier posible mensaje lingüístico -también el de la imaginación- presente implícita o explícitamente en el metalenguaje de lo fotográfico [9].

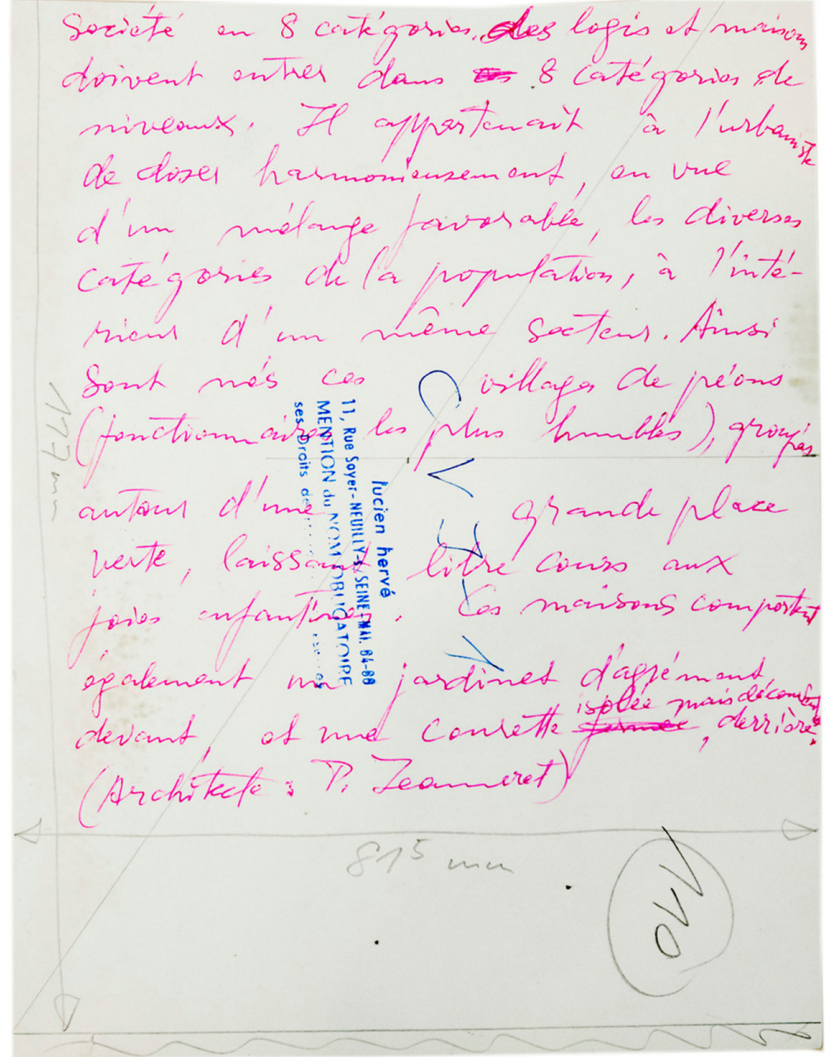

7. Reverso de una fotografía (ca1962) de Lucien Hervé de uno de los proyectos realizados por el arquitecto Pierre Jeanneret en la India. Hervé, a mano, anota una amplia descripción del proyecto para su catalogación y difusión. Collection Canadian Centre for Architecture, Montréal. ARCH269113 0SG1
8. Dorso de una fotografía del fotógrafo Gad Borel-Boissonas (1930). Escrito en francés, a lápiz, se lee: «En el apartamento de Le Corbusier, casa Clarté, Ginebra: Dacy Jeanneret y su madre (de espaldas). En el balcón: P. Jeanneret y Le Corbusier». Sin esta descripción no sería posible reconocer en primera instancia a las personas que aparecen en la fotografía, al estar todos situados de espaldas a la cámara. Collection Canadian Centre for Architecture, Montréal. ARCH270004 15608601

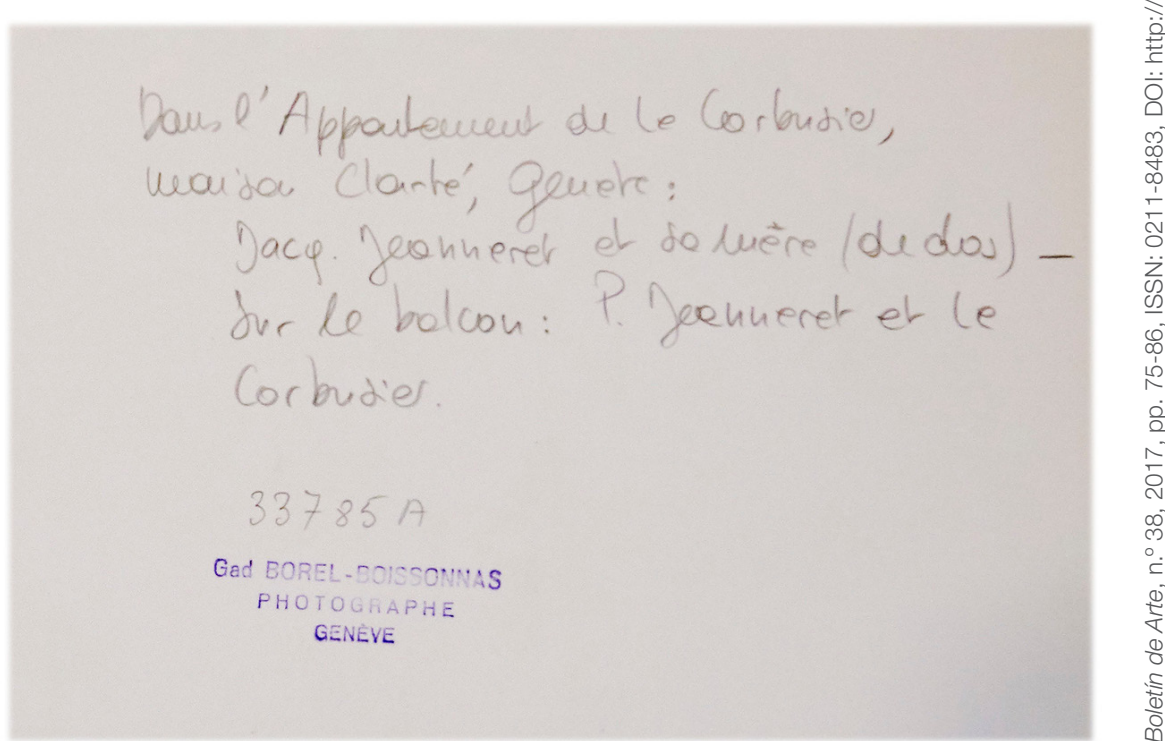




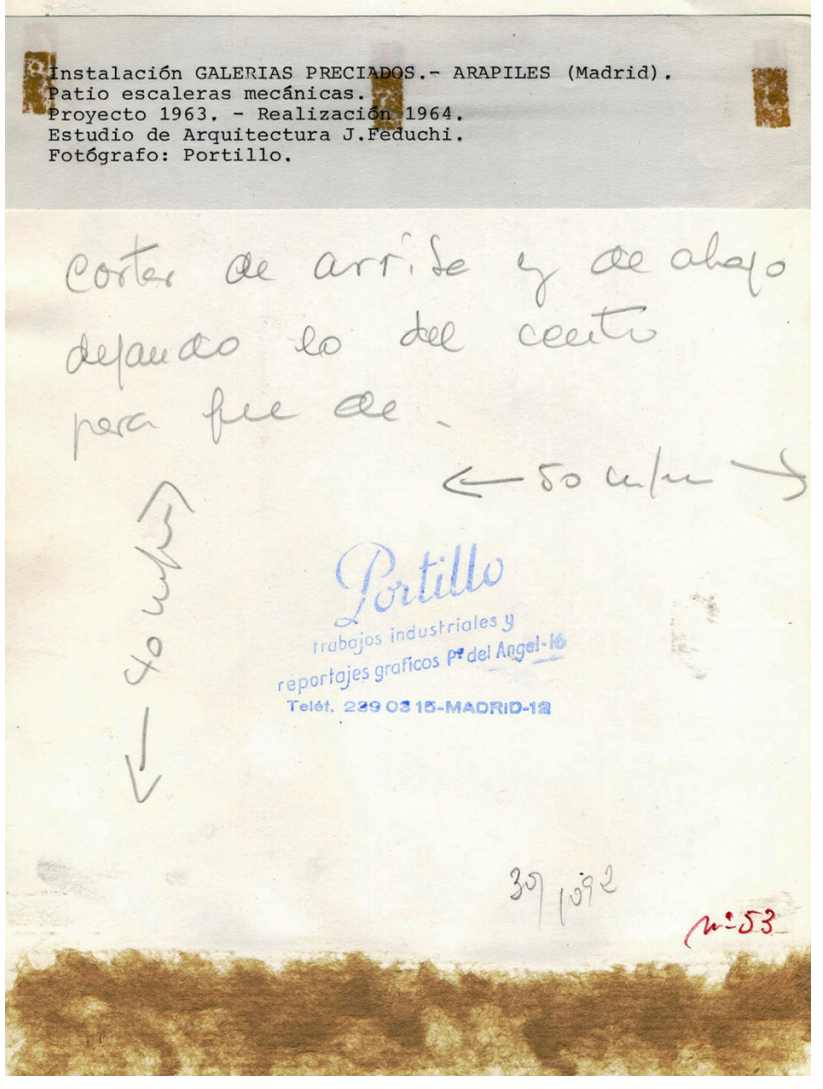

9. Reverso de una fotografía del Instituto de Formación del Profesorado de Enseñanza Media y Profesional (Madrid, 1955), obra del arquitecto Miguel Fisac perteneciente al archivo de Carlos Flores y publicada en su libro de 1961 Arquitectura Española Contemporánea (Aguilar, Madrid)

Como apunta Federico Soriano (2009: 71) seguramente el hecho de escribir en el dorso esos textos y datos ocultos liberan al fotógrafo o al arquitecto de una cierta responsabilidad o deuda en relación a la propia imagen y permiten abandonar la propia fotografía a la suerte de su olvido [10]:

Las fotografías no son recuerdos sino olvidos. Hacemos una fotografía para poder olvidar los nombres y las historias que hay detrás. La gente necesita escribir en el envés de cada una de ellas lo que aparece; la fecha, los datos que se olvidarán al hacer la foto. Estamos tranquilos al olvidar las caras de los seres queridos porque tenemos fotografías suyas. Hacemos un álbum de nuestros recuerdos porque así los borraremos de nuestra vivencia diaria. También las fotografías de arquitectura nos hacen olvidar los espacios, las percepciones, las

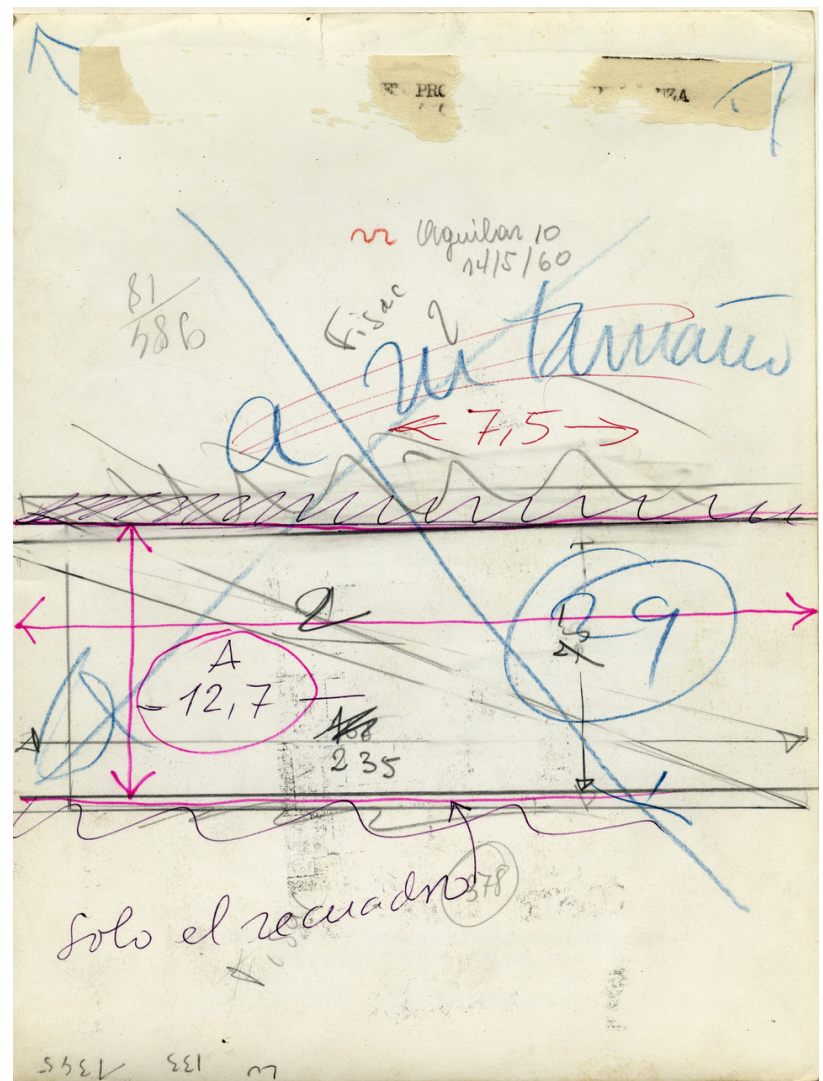

10. Reverso de una fotografía de Cristóbal Portillo de la instalación de Galerías Preciados en Arapiles (Madrid, 1963) obra de Javier Feduchi, perteneciente al legado Nueva Forma de la Biblioteca de la Universidad de Valladolid plantas, los detalles, hacemos fotografías para no tener que pensar en arquitectura. Para no ocupar nuestra cabeza con las percepciones y las ideas.

\section{Agradecimientos}

La investigación que presenta este artículo se circunscribe a la tarea llevada a cabo en torno al proyecto de investigación FAME («Fotografía y arquitectura moderna en España, 19251962») del Programa Nacional de Proyectos de Investigación Fundamental en el marco del VI Programa Nacional de Investigación Científica, Desarrollo e Innovación Tecnológica 2008-2011 (Ref. HAR2012-34628), del Ministerio de Economía y Competitividad. Agradecemos por tanto al Ministerio 
de Economía y Competitividad la confiada depositada en nuestro trabajo así como a todas las entidades promotoras y observadoras del mismo, en particular a las instituciones y a los archivos públicos y privados que nos han permitido realizar esta ambiciosa labor de documentación e investi- gación durante los últimos cuatro años (2013-2016). Quiero agradecer también los consejos e información recibida para elaborar este texto por parte de Alberto Martín, Chus Tudelilla, Jesús Marina y Elena Morón, cuya tesis doctoral es de obligada referencia.

\section{Notas}

1 El proyecto de investigación «Fotografía y arquitectura moderna en España, 1925-1965» (Bergera, 2014, 2015) nos ha permitido y obligado en los últimos años a visitar gran número de archivos de fotografía de arquitectura tanto dentro como fuera de España. Además de los que se encuentran en España en colegios de arquitectos $u$ otras instituciones, la reflexión que recoge este texto se amplía con el trabajo documental llevado a cabo personalmente en archivos tales como ACM de la École Polytechnique Fédérale de Lausanne, el Getty Research Institute de Los Angeles y sobre todo el Canadian Centre for Architecture de Montreal.

2 Con el fin de reforzar el argumento del presente texto, a pesar de disponerse también del anverso de las fotografías, de forma delibera he querido prescindir de ellas ilustrando únicamente el artículo con los reversos. Por otra parte, las ilustraciones que acompañan el texto son apenas un estimulante y atractivo botón de muestra de esta particular temática, de los muchos posibles. El texto no se articula en torno a ellas, entendidas como casos de estudio ejemplarizantes, sino que más sirven de acompañamiento y aval a una condensada reflexión de innegable naturaleza teórica.

\section{Bibliografía}

BARTHES, Roland (1977), «The photographic Message», en GOLDBERG, Vicki (ed.) (1981), Photography in Print: Writings from 1816 to the Present, Simon and Schuster, Nueva York.

BERGERA, Iñaki (ed.) (2014), Fotografía y arquitectura moderna en España, 1925-1965, La Fábrica, Fundación ICO, Madrid.

- (2015), Fotografía y arquitectura moderna. Contextos, protagonistas y relatos desde España, Colección arquia/temas, n. ${ }^{\circ} 39$, Fundación Arquia, Barcelona.

BUCHLOH, Benjamin (1990), "Conceptual Art 1962-1969: From the Aesthetics of Administration to the Critique of Institutions", October, n. ${ }^{\circ} 55$, pp. $105-143$.

CALVINO, Italo (1994), Seis propuestas para el próximo milenio, Siruela, Madrid.

DEL MOLINO, Sergio (2013), La hora violeta, Mondadori, Barcelona.

DERRIDA, Jacques (2002), «Structure, Sign, and Play in the Discourse of the Human Sciences», Writing and Difference, Routledge, Londres, pp. 278-294.

- (2010), Copy, Archive, Signature: A Conversation on Photography, Stanford University Press, Stanford, California.

DIDI-HUBERMAN, Georges (2010), Atlas, ¿cómo llevar el mundo a cuestas? (Catálogo de la exposición homónima), MNCARS, Madrid.

FERNÁNDEZ PELLO, Carlos (2014), «La selva documental: "hipertelia”, texto e insignificancia en las imágenes de Burden of Dreams», en FERNÁNDEZ POLANDO, Aurora (ed.) (2014), Pensar las imagen / Pensar con las imágenes, Editorial Delirio, Madrid, pp. 275-303.

FLAM, Jack (1996), Robert Smitson: The Collected Writings, University of California Press, Berkeley.

FLUSSER, Vilém (1984), «Texto e imagen», Una Filosofía de la Fotografía, Síntesis, Madrid.

FONTCUBERTA, Joan (2002), Fotografía: crisis de historia, Actar, Barcelona.

- (2010), La Cámara de Pandora: La Fotografía después de la Fotografía, Gustavo Gili, Barcelona.

GARGIANI, Roberto (2014), «Photographie et processus créatifs, 1940-1965», Le Corbusier, aventures photographiques, Fondation Le Corbusier, Éditions de la Villette, París.

ISASI, Justo (2014), «Por un puñado de fotos. Photography and modern architecture in Spain», Arquitectura Viva, n. ${ }^{\circ} 166$, pp. $49-53$. MORÓN, Elena (2005), Vacíos adjetivos. El espacio construido en la fotografía, Tesis doctoral, Escuela Técnica Superior de Arquitectura Universidad de Sevilla, Sevilla.

PEREC, Georges (2007), Especies de espacios, Montesinos, Barcelona. 
PRICE, Mary (1994), The Photograph: A Strange, Confined Space, Stanford University Press, Stanford, California.

RANCIERE, Jacques (2007), The future of the Image, Verso, Londres.

REGUERA, Galder (2008), La cara oculta de la luna: en torno a la "obra velada»: idea y ocultación en la práctica artística, Cendeac, Murcia. STAMP, Gavin (2001), «The abuse of photography», Society of Architectural Historians of Great Britain, n. ${ }^{\circ}$ 75, pp. 1-3.

STIGNEEV, Valery, «El texto en el espacio fotográfico», en YATES, Steve (ed.) (2002), Poéticas del espacio, Colección FotoGGrafía, Gustavo Gili, Barcelona.

SORIANO, Federico (2009), «Fotografiar para olvidar», 100 Hipermínimos, Lampreave, Madrid, pp. 70-71.

TAGG, John (2005), El peso de la representación, Colección FotoGGrafía, Gustavo Gili, Barcelona.

TARTÁS, Cristina y GURIDI, Rafael (2013), «Cartografías de la memoria. Aby Warburg y el atlas Mnemosyne», EGA: revista de expresión gráfica arquitectónica, n. ${ }^{\circ}$ 21, pp. 226-235. 